\title{
Cell Cycle Regulation Process
}

National Cancer Institute

\section{Source}

National Cancer Institute. Cell Cycle Regulation Process. NCI Thesaurus. Code C19598.

Control of the rate or manner of the periodic biochemical and structural events occurring during proliferation of cells; the cycle is divided into periods called: G0, Gap1 (G1), synthesis (S1), Gap2 (G2), and mitosis (M). The period runs from one division to the next. 